\title{
Cancer caregiving tasks and consequences and their associations with caregiver status and the caregiver's relationship to the patient: a survey
}

\author{
Line Lund $^{1 *}$, Lone Ross ${ }^{1}$, Morten Aagaard Petersen ${ }^{1}$ and Mogens Groenvold ${ }^{1,2}$
}

\begin{abstract}
Background: Seriously ill patients often depend on their informal caregivers to help and support them through the disease course. This study investigated informal cancer caregivers' experiences of caregiving tasks and consequences and how caregiver status (primary vs. non-primary caregiver) and the caregiver's relationship to the patient (spouse/partner, etc.) are related to these experiences.
\end{abstract}

Methods: In a cross-sectional questionnaire study, randomly selected cancer patients with a range of diagnoses and disease stages were invited to pass on the 'Cancer Caregiving Tasks, Consequences and Needs Questionnaire' (CaTCON) to 1-3 of their caregivers.

Results: A total of 590 caregivers related to 415 (55\% of 752 eligible) cancer patients participated. Large proportions of caregivers experienced substantial caregiving workload, e.g., provision of psychological support (74\%), as well as a range of negative consequences, most commonly stress (59\%). Some caregivers experienced personal growth, but relatively large proportions did not. Caregiver status and the caregiver's relationship to the patient were associated with some caregiving aspects. Primary caregivers experienced the highest caregiving workload, and non-primary caregivers experienced most problems with getting time off from work. Spouses/partners and/or parents experienced the highest workload, most lack of time for social relations, most financial difficulties, and had the greatest need for seeing a psychologist. They furthermore experienced the highest degree of personal growth and had the smallest need for living a normal life while being a caregiver. Yet, regarding the majority of caregiving aspects, no associations with caregiver status or the caregiver's relationship to the patient were found.

Conclusions: Overall, the findings confirm that cancer caregiving is burdensome. The primary and the closest caregivers seemed to take on most caregiving tasks, but, contrary to expectations, regarding the majority of caregiving consequences non-primary and more distant caregivers were affected to the same degree as the primary and closest caregivers. Initiatives and interventions to support not only the primary caregivers are therefore warranted.

Keywords: Cancer, Informal caregivers, Cross-sectional questionnaire study, Caregiving tasks, Caregiving consequences, Caregiver status, Caregiver's relationship to the patient

\footnotetext{
* Correspondence: lundline@gmail.com

${ }^{1}$ The Research Unit, Department of Palliative Medicine, Bispebjerg and Frederiksberg Hospitals and University of Copenhagen, Bispebjerg Bakke 23, DK-2400 Copenhagen, NV, Denmark

Full list of author information is available at the end of the article
} 


\section{Background}

Informal caregivers to patients with a life-threatening disease such as cancer are often deeply involved in the patient's disease and provide extraordinary and uncompensated care. The caregivers may take on a range of disease related tasks, e.g., provision of emotional support [1-3], physical care [4-7], treatment monitoring $[1,4,5,8]$, and symptom management $[1,5,8]$. In addition, the caregivers also frequently take over or assist with everyday tasks [8], such as cooking [9], housekeeping [4,5,7], and child care [9], if the patient has become unable to carry out these [1]. These tasks can be emotionally, physically, socially, and financially demanding [10], and $10-50 \%$ of the caregivers experience considerable strain $[11,12]$. Negative consequences of caregiving, such as depression [1,3-6,10,13-18], anxiety [1,4-7,10,13-16], distress/stress [3,7,13-15,17], fatigue $[1,6,7,15,16]$, and insomnia $[1,5-7,15,16]$, have frequently been reported. Thus, caregiving may have significant costs to the caregivers' own well-being $[3,10]$. The strain on the caregiver may also affect the patient [19]. Yet, to take on the responsibility as a caregiver is often regarded an ethical, social, and compassionate obligation and by living up to this obligation and doing 'the right thing', the deed can be motivating and rewarding. Thus, positive consequences of caregiving, such as improved sense of self-worth $[5,13,17]$, post-traumatic growth [17], relationship enhancement $[20,21]$, and altered perspective on living [20], have also been described.

Relatively few large caregiver surveys have been conducted (but see e.g., [8]), i.e., the studies documenting caregiving tasks and consequences have often included relatively small samples of caregivers, many have been qualitative studies, or the studies have elucidated only one or few aspects of being a caregiver. The majority of studies have focused on caregivers with the status as primary caregiver (typically appointed by the patient) or spouses/partners. Not much attention has been paid to non-primary caregivers or caregivers with more distant relationships to the patients than spouses/partners.

The present study is a survey including a large sample of cancer caregivers representing various caregiver status (appointed primary or non-primary caregiver) and formal relationships to the patient (spouses/partners, children, etc.). The questionnaire used is the 'Cancer Caregiving Tasks, Consequences and Needs Questionnaire' (CaTCoN) which elucidates a broad range of caregiving aspects. The CaTCoN was developed and validated in order to map the caregiving experience more comprehensively than existing instruments [22].

The aims of this study were:

A) To measure the proportions of cancer caregivers experiencing burdensome caregiving tasks and consequences
B) To investigate how caregiver status and the caregiver's relationship to the patient are related to the caregiving tasks and consequences.

Regarding aim B, our hypotheses were that primary caregivers and caregivers with the closest relationships to the patient took on more caregiving tasks and experienced more consequences of being a caregiver than non-primary caregivers and caregivers with more distant relationships to the patients, respectively.

\section{Methods}

\section{Study population and questionnaire distribution}

In January-July 2010, a sample of cancer patients was randomly selected from medical records in five hospital departments (departments of oncology, haematology, gynaecology and surgery) at three different hospitals in the Copenhagen area. Non-terminal, adult (18+ years) male and female patients with a range of cancer diagnoses and disease stages were included.

Caregiver questionnaires (three copies) were sent to the patients, asking them to pass the questionnaires on to one to three adult caregivers involved in their disease course. Patients reporting that no caregivers had been involved in their disease course were excluded. The questionnaires were identical except that one questionnaire was directed towards and marked 'primary caregiver'.

The study complied with the Helsinki II Declaration and was approved by the Danish Data Protection Board (jr.no. BBH-2009-01). The protocol was presented to the National Committee on Health Research Ethics (protocol no. H-1-2010-FSP-22) and was found not to require formal approval.

\section{Measures \\ Cancer caregiving tasks, consequences and needs questionnaire (CaTCoN)}

The 72-item CaTCoN measures cancer caregiving tasks and consequences and the caregivers' needs mainly concerning information from and communication and contact with health care professionals [22]. The validity and reliability of the CaTCoN were evaluated by using psychometric analyses and tests of convergent/discriminant validity with the existing instruments FAMCARE [23] and FIN [24] and were found to be satisfactory: Cronbachs alpha ranged 0.65-0.95, and hypothesized convergent and divergent $\mathrm{CaTCON}$ and FAMCARE/FIN scales correlated 0.59-0.74 and $-0.11-0.25$, respectively [25]. The CaTCoN contains nine subscales (each containing between two and 14 items) and 31 single items (including two open-ended items for qualitative comments). The majority of items contain four ordinal response categories and a 'don't know/not relevant' category. Single item scores are expressed on a scale ranging 0 (no burden/problems) to 100 (maximum 
burden/problems), excluding the 'don't know/not relevant' category. Subscale scores are estimated as the mean of 'information carrying' item scores (i.e., responses in all other categories than the 'don't know/not relevant' category) also expressed on a range from 0 (no burden/problems) to 100 (maximum burden/problems). The subscale scores used in the present analyses were calculated if responses to half or less of the items were missing or in the 'don't know/not relevant' category.

The caregivers were also asked a range of sociodemographic questions (see 'Variables' section).

\section{Variables}

\section{Outcomes}

This article reports the results concerning caregiving tasks, i.e., the $\mathrm{CaTCoN}$ subscale 'caregiving workload' (items 1a, $1 \mathrm{~b}, 1 \mathrm{c}, 3,4$ ) and single item 2 , and caregiving consequences, i.e., the $\mathrm{CaTCoN}$ subscales 'lack of time for social relations' (items 6c, 6d) and 'lack of personal growth' (items 6e, 6f, $6 \mathrm{~g}$ ), and single items $6 \mathrm{a}, 6 \mathrm{~b}, 7,8,9,20,34,38,39,40$ and 41 $[22,25]$ as shown in Table 1, left column.

\section{Independent variables}

This study focused on two independent variables: 1) 'caregiver status', classified as primary or non-primary caregiver to the patient based on the mark on the questionnaire and 2) 'the caregiver's relationship to the patient', classified as spouse/partner, child, parent, sibling, or other (e.g., friend, colleague) based on information in the questionnaire. Among the latter, we hypothesized that spouses/ partners and (for young patients) the patient's parents would have the closest relationships to the patients.

The following independent variables were also included: caregiver gender, age, marital status, having children or not, education, employment, job description, and place of living; and patient gender, age, diagnosis, disease stage, inclusion group (i.e., diagnosed within the last year, diagnosed more than a year ago and in treatment, or diagnosed more than a year ago and off treatment), time since diagnosis, and type of hospital department (from which the patient was sampled).

\section{Data analysis}

The proportion of patients with at least one participating caregiver was calculated. Characteristics (shown in Table 2, left column) of eligible patients with at least one participating caregiver and eligible patients without a participating caregiver were compared using logistic regression analysis. Similarly, and regarding the same patient characteristics, the patients with a participating primary caregiver were compared to those without a participating primary caregiver (but with at least one participating non-primary caregiver).

The association between caregiver status and the caregiver's relationship to the patient was investigated. Furthermore, the associations between the independent variables and whether or not the participating spouse/partner was the primary caregiver were investigated using logistic regression analysis.

For the total sample of caregivers, frequencies and mean scores for each of the 22 included $\mathrm{CaTCoN}$ items and mean scores for the three subscales were calculated.

The associations between independent variables and the $\mathrm{CaTCoN}$ single items and subscales were tested using regression analyses. In the regression analyses, adjustment was made to account for the fact that caregivers related to the same patient were not independent (each patient could have up to three participating caregivers). The adjustment was done by using the PROC MIXED procedure for subscales and the PROC GLIMMIX procedure for single items in the SAS statistical package $\mathrm{v}$. 9.3 [26]. For the linear regression analysis with the three $\mathrm{CaTCoN}$ subscales as dependent variables, the normal distribution of the subscale was examined by inspection of residuals, q-q plot, skewness, and kurtosis. To be able to use the PROC GLIMMIX procedure, single items with four ordinal categories were dichotomised in the middle, creating a positive versus a negative response.

In the regression analysis, independent variables associated at a significance level $<0.20$ with the particular outcome in an initial univariate regression analysis were entered in a multiple regression model. Backward stepwise regression analysis was undertaken for model building. A significance level of 0.05 was chosen for the multivariate analyses. Only data from the multivariate analyses is shown.

Finally, the association between caregiver status, relationship to the patient, and perceived stress was examined in a three-way table.

\section{Results}

\section{Study population}

A total of 856 patients were identified and were sent questionnaires to pass on to their caregivers. Subsequently, 104 of these patients were excluded from the study as they did not meet the inclusion criteria (e.g., the patients were terminal/deceased or replied that no caregivers had been involved in the disease course). The remaining 752 patients were eligible.

From the 752 eligible patients, 598 caregivers responded to the questionnaire. Of these, eight questionnaires were excluded because the caregiver was $<18$ years old $(n=5)$, or the questionnaire was filled in by the patient $(n=3)$, resulting in a final sample of 590 participating caregivers included in the analyses.

\section{Characteristics of patients with one or more participating caregivers}

The 590 participating caregivers were related to 415 (55\%) of the 752 eligible patients as some patients had 


\section{CaTCoN items}

Frequencies (\%)

Mean $^{\mathrm{a}}$

Std Dev

\section{CaTCoN single items}

\section{Caregivng tasks}

To what extent have you had to provide:

1a. Practical help to the patient?

1b. Personal care to the patient?

1c. Psychological support to the patient?

2. It is the responsibility of the hospitals to make referrals and appointments for examination and treatment. Have

you felt that you have been partially responsible for

keeping track of whether the patient has been referred

and called for examinations and treatments quickly and correctly?

3. Have you felt that you have had too much

responsibility in relation to home care (personal care,

medications, etc.)?

4. Have you spent time transporting the patient?

\section{Caregiving consequences}

Has the patient's cancer disease:

6a. Caused you stress?

6b. Had a negative effect on your own physical health? 6c. Meant that you have not had enough time for (the rest of your family?

6d. Meant that you have not had enough time for (the rest of) your friends/acquaintances?

6e. Increased you awareness of the important things in life?

$6 \mathrm{f}$. Caused you to make positive changes?

$6 \mathrm{~g}$. Made you value your relationships with other people more?

7. Have you been able to take time off, get leave of absence from work, or make similar arrangements to the extent it has been necessary?

8. Has the patient's illness meant that you have had to be absent from work so much that it has posed problems at your workplace?
13

49

3

Not at all

62

60

No, not at all

23

27

Yes, some

23

No, not at all

9

52

49

45

5

19

10

Always/almost always

40

Not at all

50

Mostly

13

4

To a low degree

$\begin{array}{ccc}\text { Yes, a little } & \text { Yes, some } & \text { Yes, a lot } \\ 29 & 28 & 31 \\ 29 & 11 & 5 \\ 28 & 13 & 6 \\ 28 & 14 & 9 \\ 18 & 30 & 45 \\ 39 & & \\ 26 & 24 & 11 \\ & 31 & 29\end{array}$

Yes, a lot

Don't know/not relevant Missing

Don't know/not relevant Missing

29

8

1
2

2

56.9

34.4

$25.7 \quad 32.0$

$71.9 \quad 28.7$

a high degree Don't know/not relevant Missing

4

20.8

Don't know/not relevant

2

2

3

9

45

29

Only sometimes

Rarely/never

4

Don't know/not relevant Missing

17.3

28.4

To some degree

To a high degre

Don't know/not relevant Missing

11.6 
Table 1 Frequencies (\%) and mean scores of responses regarding caregiving tasks and consequences ( $\mathbf{n}=\mathbf{5 9 0}$ caregivers) (Continued)

9. Have you experienced negative financial consequences

of being a caregiver?

20. Have you needed financial counselling?

71

34. Have you needed to see a psychologist as a

No Yes

11

Yes

$94 \quad 6$

consequence of the patient's illness?

80

20

38. Have you had the need to be able to take a break

from the practical tasks (in the role of caregiver) in

connection to the illness?

39. Have you felt that you have had the possibility to

take a break from the practical tasks?

40. Have you had the need to lead a 'normal' life at the same time as you have been a caregiver?

41. Have you felt that you have had the possibility to

lead a 'normal' life at the same time as being a caregiver?

To a high degree

6

18

38

35

\section{CatCoN subscales}

Caregiving workload (items 1a, 1b, 1c, 3, 4)

Lack of personal growth (items $6 \mathrm{e}, 6 \mathrm{f}, 6 \mathrm{~g}$ )

Lack of time for social relations (items $6 c, 6 d$ )

a Mean score range from 0 (no burden/problems) to 100 (maximum burden/problems). 
Table 2 Patient characteristics

\begin{tabular}{|c|c|c|c|c|c|c|}
\hline & & $\begin{array}{l}\text { Eligible } \\
\text { patients }\end{array}$ & $\begin{array}{l}\text { Patients with } \\
\text { participating caregiver(s) }\end{array}$ & $\begin{array}{c}\text { Proportion } \\
\text { participating (\%) }\end{array}$ & $\begin{array}{l}\text { Odds } \\
\text { ratio" }(\mathrm{OR})\end{array}$ & $\begin{array}{l}\text { 95\% confidence } \\
\text { interval }\end{array}$ \\
\hline All & & 752 & 415 & 55 & & \\
\hline \multirow[t]{2}{*}{ Gender } & Female & 445 & 238 & 53 & 1.00 & - \\
\hline & Male & 307 & 177 & 58 & 1.18 & $(0.88-1.59)$ \\
\hline \multirow[t]{5}{*}{ Age } & $18-39$ years & 85 & 43 & 51 & 0.88 & $(0.54-1.45)$ \\
\hline & $40-49$ years & 77 & 40 & 52 & 0.93 & $(0.56-1.56)$ \\
\hline & $50-59$ years & 122 & 71 & 58 & 1.20 & $(0.77-1.86)$ \\
\hline & $60-69$ years & 240 & 129 & 54 & 1.00 & - \\
\hline & $70+$ & 228 & 132 & 58 & 1.18 & $(0.82-1.71)$ \\
\hline \multirow[t]{7}{*}{ Diagnosis } & Head and neck & 66 & 37 & 56 & 1.11 & $(0.63-1.97)$ \\
\hline & Gastrointestinal & 146 & 85 & 58 & 1.22 & $(0.78-1.89)$ \\
\hline & Gynaecological & 176 & 94 & 53 & 1.00 & - \\
\hline & Breast & 60 & 28 & 47 & 0.76 & $(0.42-1.37)$ \\
\hline & Leukaemia & 148 & 79 & 53 & 1.00 & $(0.64-1.55)$ \\
\hline & Other (lung, prostate, urinary etc.) & 155 & 91 & 59 & 1.56 & $(0.83-2.95)$ \\
\hline & Missing & 1 & 1 & 100 & - & - \\
\hline \multirow[t]{5}{*}{ Stage $(T N M)^{* *}$} & 1 & 162 & 76 & 47 & 1.00 & - \\
\hline & 2 & 109 & 48 & 44 & 0.89 & $(0.55-1.45)$ \\
\hline & 3 & 79 & 57 & 72 & 2.93 & $(1.64-5.24)$ \\
\hline & 4 & 106 & 63 & 59 & 1.66 & $(1.01-2.72)$ \\
\hline & Cancer with no TNM stage/missing & 296 & 171 & 58 & - & - \\
\hline \multirow{4}{*}{$\begin{array}{l}\text { Inclusion } \\
\text { group* }\end{array}$} & 1 (diagnosed within the last year) & 321 & 187 & 58 & 1.42 & $(1.04-1.94)$ \\
\hline & $\begin{array}{l}2 \text { (diagnosed }>1 \text { year ago, and in } \\
\text { treatment) }\end{array}$ & 96 & 60 & 63 & 1.70 & $(1.07-2.71)$ \\
\hline & 3 (diagnosed $>1$ ago, and off treatment) & 327 & 162 & 50 & 1.00 & - \\
\hline & Missing & 8 & 6 & 75 & - & - \\
\hline \multirow{6}{*}{$\begin{array}{l}\text { Time since } \\
\text { diagnosis }\end{array}$} & $<6$ months & 179 & 100 & 56 & 0.99 & $(0.66-1.50)$ \\
\hline & 6-12 months & 138 & 85 & 62 & 1.26 & $(0.80-1.98)$ \\
\hline & $1-2$ years & 120 & 64 & 53 & 0.90 & $(0.56-1.42)$ \\
\hline & $2-5$ years & 182 & 102 & 56 & 1.00 & - \\
\hline & $>5$ years & 129 & 61 & 47 & 0.70 & $(0.45-1.11)$ \\
\hline & Missing & 4 & 3 & 75 & - & - \\
\hline \multirow{3}{*}{$\begin{array}{l}\text { Hospital } \\
\text { department }\end{array}$} & Oncology/Haematology & 569 & 316 & 56 & 1.00 & - \\
\hline & Gynaecology & 120 & 58 & 48 & 0.75 & $(0.51-1.11)$ \\
\hline & Surgery & 63 & 41 & 65 & 1.49 & $(0.87-2.57)$ \\
\hline \multirow{3}{*}{$\begin{array}{l}\text { Marital } \\
\text { status** }\end{array}$} & Married/cohabiting & 294 & 266 & 90 & 1.00 & - \\
\hline & Other (divorced/separated, single, widow(er)) & 128 & 91 & 71 & 0.26 & $(0.15-0.45)$ \\
\hline & Missing & 330 & 58 & 18 & - & - \\
\hline \multirow[t]{6}{*}{ Education } & No education & 58 & 45 & 78 & 0.87 & $(0.39-1.90)$ \\
\hline & Student/under education & 6 & 5 & 83 & 1.25 & $(0.14-11.31)$ \\
\hline & $\begin{array}{l}\text { Non-theoretical or short education } \\
\text { ( }<1 \text { year) }\end{array}$ & 93 & 82 & 88 & 1.86 & $(0.84-4.14)$ \\
\hline & Short theoretical education ( $1-3$ years) & 92 & 84 & 91 & 2.63 & $(1.09-6.30)$ \\
\hline & Long theoretical education (>3 years) & 100 & 80 & 80 & 1.00 & - \\
\hline & University education & 56 & 49 & 88 & 1.75 & $(0.69-4.44)$ \\
\hline
\end{tabular}


Table 2 Patient characteristics (Continued)

\begin{tabular}{|c|c|c|c|c|c|c|}
\hline & Missing & 347 & 70 & 20 & - & - \\
\hline \multirow{6}{*}{$\begin{array}{l}\text { Job } \\
\text { description }\end{array}$} & Self-employed & 53 & 47 & 89 & 1.44 & $(0.57-3.61)$ \\
\hline & Salaried & 232 & 196 & 84 & 1.00 & - \\
\hline & Skilled worker & 58 & 49 & 84 & 1.00 & $(0.45-2.21)$ \\
\hline & Un-skilled worker & 37 & 30 & 81 & 0.79 & $(0.32-1.93)$ \\
\hline & Assisting spouse & 9 & 7 & 78 & 0.64 & $(0.13-3.22)$ \\
\hline & Missing & 363 & 86 & 24 & - & - \\
\hline \multirow{6}{*}{$\begin{array}{l}\text { Employment } \\
\text { before cancer }\end{array}$} & Full time & 176 & 153 & 87 & 1.00 & - \\
\hline & Part time & 45 & 42 & 93 & 2.10 & $(0.60-7.35)$ \\
\hline & Old age pension & 119 & 100 & 84 & 0.79 & $(0.41-1.53)$ \\
\hline & Early retirement pension & 57 & 44 & 77 & 0.51 & $(0.24-1.09)$ \\
\hline & Other (student, un-employed, housewife) & 19 & 16 & 84 & 0.80 & $(0.22-2.97)$ \\
\hline & Missing & 336 & 60 & 18 & - & - \\
\hline \multirow{6}{*}{$\begin{array}{l}\text { Current } \\
\text { employment }\end{array}$} & Full time & 124 & 108 & 87 & 1.52 & $(0.79-2.94)$ \\
\hline & Part time & 43 & 40 & 93 & 3.01 & $(0.87-10.37)$ \\
\hline & Old age pension & 163 & 133 & 82 & 1.00 & - \\
\hline & Early retirement pension & 65 & 55 & 85 & 1.24 & $(0.57-2.71)$ \\
\hline & Other (student, un-employed, housewife) & 21 & 17 & 81 & 0.96 & $(0.30-3.06)$ \\
\hline & Missing & 336 & 62 & 18 & - & - \\
\hline \multirow[t]{5}{*}{ Place of living } & In the country/village & 74 & 67 & 91 & 1.64 & $(0.69-3.89)$ \\
\hline & Smaller provincial town & 65 & 51 & 78 & 0.62 & $(0.31-1.26)$ \\
\hline & Bigger provincial town & 64 & 53 & 83 & 0.83 & $(0.39-1.75)$ \\
\hline & City or suburb & 219 & 187 & 85 & 1.00 & - \\
\hline & Missing & 330 & 57 & 17 & - & - \\
\hline
\end{tabular}

Characteristics (obtained from medical records and self-reported) of the 752 eligible patients and the 415 patients with at least one participating caregiver, and comparison (OR) of characteristics of eligible patients with at least one participating caregiver and eligible patients without a participating caregiver.

"Odds for participation is analysed using logistic regression analysis.

*0.05 > p $>0.01$ in the logistic regression analysis.

${ }^{* *} \mathrm{p}<0.001$ in the logistic regression analysis.

provided more than one caregiver. Characteristics of eligible patients and 'participating patients' (patients with at least one participating caregiver) are shown in Table 2.

'Participation' was most common among married patients and among patients with stage three disease and less common among patients diagnosed with cancer more than a year ago and currently off treatment (inclusion group 3) (Table 2).

'Participating patients' with a participating primary caregiver did not differ from 'participating patients' without a participating primary caregiver (data not shown).

\section{Characteristics of the participating caregivers}

Characteristics of the participating caregivers $(n=590)$ are shown in Table 3. Concerning caregiver status, about half of the caregivers (51\%) were primary caregivers. The caregivers' relationship to the patients were spouses/partners (46\%), children (31\%), parents (8\%), siblings (7\%), and other, e.g., friends or colleagues (8\%).
Table 4 illustrates the association between caregiver status and the caregiver's relationship to the patient. Of the patients who had a spouse/partner among their participating caregivers, $64 \%$ viewed the spouse/partner as the primary caregiver. Thirty-six percent of the patients with a parent among their participating caregivers viewed the parent as the primary caregiver (of these patients, $88 \%$ were below 40 years of age, data not shown).

Whether or not the participating spouse/partner was the primary caregiver was significantly associated $(\mathrm{p}=0.0351)$ with the severity of disease: Among patients with stage 1 disease, $77 \%$ of the participating spouses/partners were primary caregivers. This proportion dropped to 59\% and 56\% for patients with stage 2 and 3 disease, respectively, and among patients with stage 4 disease, $49 \%$ of the participating spouses/partners were primary caregivers (data not shown).

\section{Frequency of problems}

The distribution of the 590 participating caregivers' answers to the 22 CaTCoN items is shown in Table 1. 
Table 3 Caregiver characteristics

\begin{tabular}{|c|c|c|}
\hline & n (=590) & $\%$ \\
\hline \multicolumn{3}{|l|}{ Caregiver status } \\
\hline Primary caregiver & 299 & 51 \\
\hline Non-primary caregiver & 291 & 49 \\
\hline \multicolumn{3}{|l|}{ Relationship to the patient } \\
\hline Spouse/partner & 271 & 46 \\
\hline Child of the patient & 182 & 31 \\
\hline Parent to the patient & 47 & 8 \\
\hline Sibling & 39 & 7 \\
\hline Other (e.g., friend, colleague) & 48 & 8 \\
\hline Missing & 3 & 1 \\
\hline \multicolumn{3}{|l|}{ Gender } \\
\hline Female & 358 & 61 \\
\hline Male & 228 & 39 \\
\hline Missing & 4 & 1 \\
\hline \multicolumn{3}{|l|}{ Age (years) } \\
\hline $18-39$ & 117 & 19 \\
\hline $40-49$ & 120 & 20 \\
\hline 50-59 & 128 & 22 \\
\hline $60-69$ & 143 & 24 \\
\hline $70+$ & 79 & 13 \\
\hline Missing & 3 & 1 \\
\hline \multicolumn{3}{|l|}{ Marital status } \\
\hline Married/cohabiting & 478 & 81 \\
\hline Other (divorced/separated, single, widow(er)) & 108 & 18 \\
\hline Missing & 4 & 1 \\
\hline \multicolumn{3}{|l|}{ Have children } \\
\hline No & 114 & 19 \\
\hline Yes & 470 & 80 \\
\hline Missing & 6 & 1 \\
\hline \multicolumn{3}{|l|}{ Place of living } \\
\hline Country/village & 94 & 16 \\
\hline Smaller provincial town & 97 & 16 \\
\hline Bigger provincial town & 90 & 15 \\
\hline City or suburbs & 301 & 51 \\
\hline Missing & 8 & 1 \\
\hline \multicolumn{3}{|l|}{ Level of education } \\
\hline No education & 43 & 7 \\
\hline Student & 18 & 3 \\
\hline Non-theoretical or short education ( $<1$ year) & 104 & 18 \\
\hline Short theoretical education (1-3 years) & 109 & 18 \\
\hline Long theoretical education (>3 years) & 188 & 32 \\
\hline University education & 106 & 18 \\
\hline Missing & 22 & 4 \\
\hline
\end{tabular}

Table 3 Caregiver characteristics (Continued)

\begin{tabular}{lcc}
\hline Job description & & \\
Self-employed & 56 & 9 \\
Salaried & 345 & 58 \\
Skilled worker & 82 & 14 \\
Un-skilled worker & 40 & 7 \\
Assisting spouse & 12 & 2 \\
Missing & 55 & 9 \\
Employment & & \\
Full time & 281 & 48 \\
Part time & 91 & 15 \\
Old age pension & 112 & 19 \\
Early retirement pension & 59 & 10 \\
Other (student, un-employed, housewife) & 37 & 6 \\
Missing & 10 & 2 \\
\hline
\end{tabular}

\section{Caregiving tasks}

Fifty-three percent of the caregivers provided some or a lot of practical help to the patient, $20 \%$ provided some or a lot of personal care, and $74 \%$ provided some or a lot of psychological support. Although the items indicated that ideally this should not be the case, $17 \%$ of the caregivers felt that they to some or to a high degree had been partially responsible for coordinating examinations and treatments, and $15 \%$ felt that they to some or to a high degree had had too much responsibility in relation to home care. About half (48\%) had spent some or a lot of time transporting the patient.

\section{Consequences of caregiving}

More than half of the caregivers (59\%) reported that the patient's illness had caused them some or a lot of stress, and $16 \%$ reported some or a lot of negative effect on their own physical health. Twenty percent had needed to see a psychologist. Nineteen percent and 23\% of the caregivers reported that they had not had enough time for their

Table 4 The association between caregiver status and the caregiver's relationship to the patient

\begin{tabular}{llll}
\hline & $\begin{array}{l}\text { Primary } \\
\text { caregiver }\end{array}$ & $\begin{array}{l}\text { Non-primary } \\
\text { caregiver }\end{array}$ & Total \\
\hline Spouse/partner & $174(64 \%)$ & $97(36 \%)$ & 271 \\
Parent & $17(36 \%)$ & $30(64 \%)$ & 47 \\
Child & $70(39 \%)$ & $112(62 \%)$ & 182 \\
Sibling & $17(44 \%)$ & $22(56 \%)$ & 39 \\
Other (friend, colleague, etc.) & $19(40 \%)$ & $29(60 \%)$ & 48 \\
Missing & - & - & 3 \\
Total & 297 & 290 & 590 \\
\hline
\end{tabular}


family and friends, respectively. Twenty-two percent had had the need to take a break from the practical tasks to some or to a high degree, and $67 \%$ had had the need to lead a 'normal' life while being a caregiver to some or to a high degree. Yet, $28 \%$ and $21 \%$, respectively, felt that they had had the possibility for this only to a low degree or not at all.

Eight percent had only sometimes or rarely/never been able to take the necessary time off from work etc., and for $5 \%$ the absence from work had caused them problems at their workplace. Nine percent had experienced financial consequences of being a caregiver to some or to a high degree, and $6 \%$ had needed financial counselling.

Increased awareness of the important things in life, positive changes, and valuing relationships to other people more was experienced only a little or not at all by $23 \%$, $58 \%$, and $36 \%$ of the caregivers, respectively.

\section{Multivariate analysis}

The associations between the CaTCoN outcomes and the two independent variables caregiver status and the caregiver's relationship to the patient are shown in Table 5 (the associations between the CaTCoN outcomes and the remaining included independent variables can be found in Additional file 1).

The status of the caregiver was associated with two out of 15 outcomes. Primary caregivers had higher workload than non-primary caregivers, and non-primary caregivers had more problems with getting time off from work than primary caregivers.

The caregiver's relationship to the patient was associated with six out of 15 outcomes. Parents to the patient had the highest workload, followed by the spouse/partner. Friends, colleagues etc. experienced the lowest degree of personal growth whereas parents to the patient, followed by the spouse/partner, experienced the highest degree. Parents to the patient, followed by the patient's spouse/ partner, experienced most lack of time for social relations. Spouses/partners experienced most financial difficulties. Parents to the patient, closely followed by the patient's spouse/partner, had the greatest need for seeing a psychologist. Friends, colleagues etc. had the greatest need for living a normal life while being a caregiver whereas parents to the patient, followed by the spouse/partner, had the smallest need.

Regarding the remaining independent variables (see Additional file 1), caregiver employment and caregiver gender were most often associated with the outcomes. Caregiver employment was associated with five outcomes, but no clear picture emerged regarding which groups were the most burdened. Caregiver gender was associated with four outcomes; women experienced more problems, but also more personal growth in relation to being a caregiver than men.

\section{Caregiver status and the caregiver's relationship to the patient associated with caregiver stress}

In line with the multivariate analysis, Table 6 shows that large proportions (47\%-71\%) of all groups of caregivers, regardless of status and the caregiver's relationship to the patient, experienced some or a lot of stress. That is, experiencing stress was not limited to the primary caregiver or the caregivers with the closest relationships to the patients.

\section{Discussion}

The present study is unique by including a large sample of caregivers and addressing their caregiving tasks and consequences by using the newly developed and validated questionnaire CaTCoN and by specifically investigating the caregiver status and the caregiver's relationship to the patient. Most previous studies addressing cancer caregiving have focused on the patient's partner/spouse (as the primary caregiver) $[3,14]$ and when caregivers with other relationships to the patient have been included, the associations between these relationships and outcomes have not been examined [18,27-29]. Also, no previous studies have investigated the caregiver's status and relationship to the patient in parallel, i.e., examined whether their associations with various outcomes are the same. This study is therefore a valuable supplement to the existing studies of cancer caregiving.

A large proportion of caregivers experienced a considerable caregiving workload related to practical help, psychological support, and transport. Negative consequences of being a caregiver were frequently experienced, e.g., 59\% of the caregivers reported stress. Thus, the study documents that being a caregiver is demanding and has its costs; it may jeopardise the caregivers' own well-being. At the same time, being a caregiver may also bring positive experiences and consequences as seen in this study. However, substantial proportions of the caregivers reported no or minimal positive changes.

Concerning the frequencies of the outcomes in this study, several of the caregiving aspects have been investigated in previous studies, but the findings cannot be compared directly due to the difference in methods. However, the overall findings of this study regarding caregiving workload are in agreement with previous findings. For instance, Yabroff and Kim (2009) found that the time spent by informal caregivers was substantial and burdensome [30], and van Ryn et al. (2011) found that large proportions of caregivers assisted with activities of daily living and moreover watched for treatment side effects (68\%), helped managing pain, nausea, or fatigue (47\%), etc. [8]. Our finding that distress/ stress is commonly experienced by caregivers is also in agreement with previous studies $[3,7,13-15,17]$, but is still remarkable in a country where focus for some time has been on the caregivers and on initiatives to help them. 
Table 5 Associations between CaTCoN outcomes and caregiver status and the caregiver's relationship to the patient $(\mathrm{n}=\mathbf{5 9 0})$

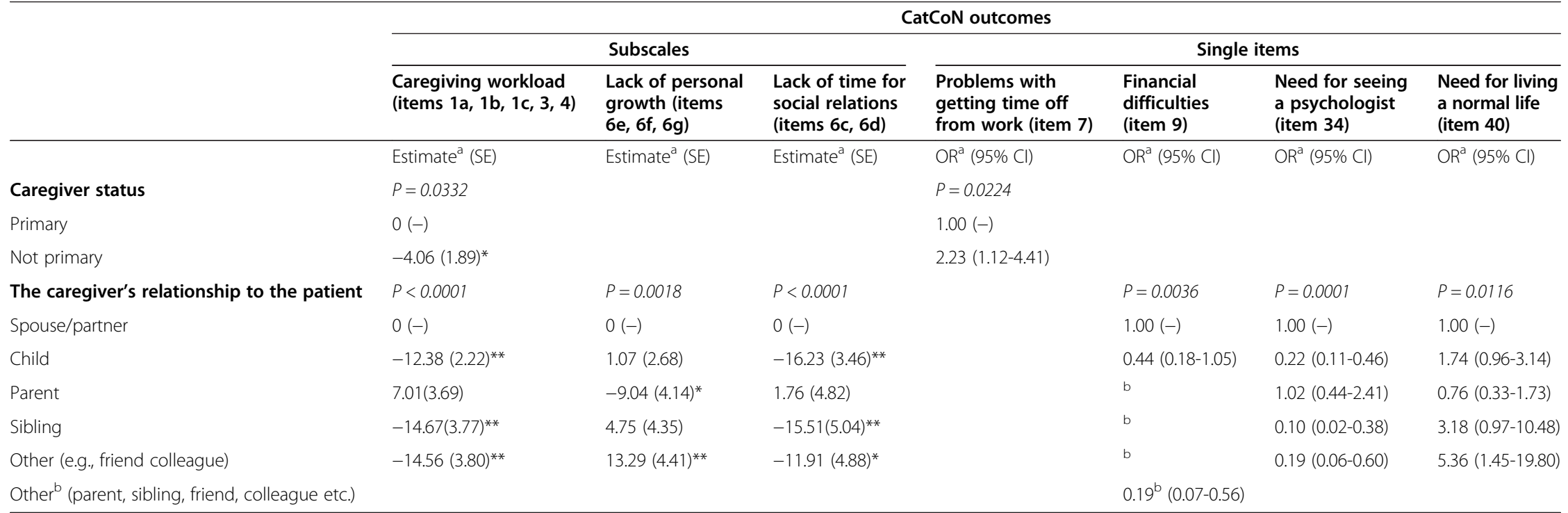

The associations were tested with multivariate regression analyses also including other independent variables. In this table, only the significant associations are shown (all in all, the associations with 15 outcomes were tested).

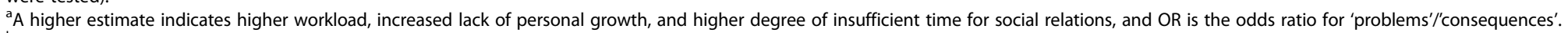

${ }^{b}$ Item 9 had a quite high number of missings and further a pronounced skewed distribution of answers. To ensure a minimum of three caregivers in each variable response category we collapsed categories in this variable into fewer categories.

${ }^{*} 0.05>\mathrm{p}>0.01,{ }^{* *} \mathrm{p}<0.01$ in the linear regression analysis of the three subscales. 
Table 6 Caregiver stress

\begin{tabular}{lll}
\hline & $\begin{array}{l}\text { Primary } \\
\text { caregiver }\end{array}$ & $\begin{array}{l}\text { Non-primary } \\
\text { caregiver }\end{array}$ \\
\hline Spouse/partner & $110 / 174(63 \%)$ & $63 / 97(65 \%)$ \\
Parent & $12 / 17(71 \%)$ & $20 / 30(67 \%)$ \\
Child & $41 / 70(59 \%)$ & $60 / 112(54 \%)$ \\
Sibling & $10 / 17(59 \%)$ & $11 / 22(50 \%)$ \\
Other (friend, colleague, etc.) & $9 / 19(47 \%)$ & $14 / 29(48 \%)$ \\
\hline
\end{tabular}

The association between caregiver status, relationship to the patient, and perceived stress: the proportions (and percentages) of caregivers who felt that the patient's disease had caused them some or a lot of stress.

This study is unique by investigating the extent to which caregiving tasks and consequences vary, depending on caregiver status and relationship to the patient. One might assume that the subdivision of the caregivers into caregiver status and the caregiver's relationship to the patient would be redundant, expecting that the closest caregivers, especially the spouses/partners (when present), would almost always have the status as primary caregivers. But Table 4 shows that actually more than one third of the participating spouses/partners were not the patients' primary caregivers, and conversely that a significant proportion of caregivers with the most distant formal relationships as friends, colleagues etc. was in fact primary caregivers. We found that the proportion of primary caregivers among the participating spouses/partners dropped with increasing severity of disease. This could reflect the involvement of several caregivers as the disease progresses. That is, in stage 1 , the spouse/partner was often the primary caregiver, and it is likely that no other caregivers were deeply involved in the management of the disease. In metastatic disease, however, more caregivers could be deeply involved in the practical tasks, in the contact with the health care system etc., and perhaps the patient considered all caregivers equally involved (or actually someone else than the spouse/partner as most involved) and passed on the primary caregiver questionnaire to someone else than the spouse.

Regarding caregiver status, one finding in this study was that primary caregivers - as hypothesized - experienced higher caregiving workload than non-primary caregivers. As the primary caregiver by definition is the caregiver most involved in the patient's disease course, this finding might seem obvious, but this study is in fact the first to focus on and document the association in this way. The other finding was that non-primary caregivers had significantly more problems with getting time off from work than primary caregivers. This finding could seem surprising as the primary caregivers would be likely to have a greater need of getting time off. Yet, perhaps being a primary caregiver entitles the caregiver to make workplace arrangements that enable them to get time off more easily. Caregiver status was not associated with any other outcomes which was contrary to expectations. For instance, it could be reasonable to assume that primary caregivers experienced more stress, more personal growth, more lack of time for social relations, and more negative physical consequences than non-primary caregivers, but neither of these hypotheses were confirmed. These findings point out that in many aspects non-primary caregivers are affected to the same degree as primary caregivers.

Regarding some aspects, the spouses/partners and parents to the patients were most burdened and experienced most consequences of being caregivers. The literature addressing the caregiver's relationship to the patient is limited, but a few studies have investigated the association between the caregiver's relationship to the patient and financial difficulties. Yabroff \& Kim (2009) and Van Houtven et al. (2010) found that spouses faced higher economic burden than other relatives and friends [30,31] which is in compliance with our finding. Still, the number of 'negative' findings in our study was surprising. For instance, we would have expected that the closest caregivers experienced most stress, but this was not confirmed. In other words, regarding several caregiving aspects, the more distant caregivers were affected to the same degree as the closest caregivers, underlining that focus should be not only on the spouses/partners and parents, but also on the remaining caregivers.

The study had a relatively equal distribution of 'participating' very ill and less ill patients: of the patients with participating caregivers who could be assigned a disease stage, $51 \%$ had early stages of cancer (TNM stages $1-2$ ), and $49 \%$ had advanced cancer (TNM stages $3-4)$. Also, about half (45\%) of the patients with participating caregivers had been diagnosed within the last year (Table 2). It is noteworthy that the patient characteristics stage, time since diagnosis, and in or off treatment were associated with only two outcomes ('need for living a normal life' and 'lack of possibility for living a normal life') out of 15 . That is, the majority of our findings concern not only caregivers to very ill patients or caregivers who has been struggling for the patient for years, but also caregivers to less ill patients and caregivers who recently have become caregivers.

This study shows that there is a need for addressing not only the patient's primary or closest caregiver which previously has been the norm, but to acknowledge that a patient has more than one caregiver and that they are all affected by the patient's disease. It is important to acknowledge all caregivers regardless of caregiver status and relationship to the patient and to include them all in studies and interventions. For the future, caregivers should be in plural.

\section{Strengths and limitations}

As in any survey, the generalizability of the findings was limited by non-participation. Nevertheless, as the caregivers 
were invited by the patients, the fact that caregivers to 55\% of the eligible patients responded appears reasonable when taking into account that some patients probably did not report to the study group that they did not have any caregivers sufficiently involved to be considered relevant for the study and instead chose not to respond. Optimally, and to estimate the caregiver response rate more accurately, data regarding how many caregivers each patient had and how many caregivers the patient chose to invite should have been collected.

The fact that the patients were 'gatekeepers' for the caregivers may have had an influence on the kind of caregivers invited; for instance, as also described in a recent study of caregivers of Girgis et al. [32], the patients might have wished to spare the most burdened caregivers from more disease related issues and as a consequence have been inclined to invite caregivers with a lower burden. This could be a reason for the relatively large non-response from primary caregivers (i.e., $28 \%$ of patients with participating caregivers had no primary caregiver participating), and if this is the case, responses from the most burdened caregivers are lacking in this study, and the results may thereby underestimate the overall level of tasks and consequences among caregivers.

Major strengths of the study are the large sample size, the measurement of a range of aspects regarding tasks and consequences of caregiving, and the elaboration of the associations with caregiver status and the caregiver's relationship to the patient.

\section{Conclusions}

Our findings confirm that cancer caregiving is burdensome: large proportions of cancer caregivers experienced substantial caregiving workload, such as provision of practical help and emotional support and help with transport. Caregivers reported a range of negative consequences of being a caregiver, most commonly stress. Some caregivers experienced personal growth, but relatively large proportions did not.

The caregiver status was only associated with two outcomes: primary caregivers experienced the highest caregiving workload, and non-primary caregivers had most problems with getting time off from work. Regarding some caregiving aspects, spouses/partners and/or parents (i.e., the caregivers with the closest relationships to the patients) seemed to be the most burdened caregivers, i.e., they experienced the highest workload, most lack of time for social relations, most financial difficulties, and had the greatest need for seeing a psychologist, but they also experienced the highest degree of personal growth and had the smallest need for living a normal life while being a caregiver.

All in all, the primary and the closest caregivers seemed to take on most caregiving tasks, but regarding the majority of caregiving consequences, non-primary and more distant caregivers were affected to the same degree as the primary and closest caregivers. Thus, initiatives and interventions to support all caregivers are warranted.

\section{Additional file}

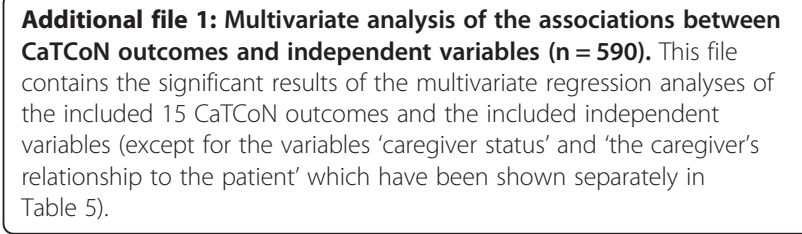

Competing interests

The authors declare that they have no competing interests.

\section{Authors' contributions}

$L L, L R$ and MG developed the study design. LL carried out the data collection. $L L$ and MAP performed the statistical analyses. $L L, L R$ and MG drafted the manuscript. All authors read and approved the final manuscript.

\section{Acknowledgements}

The research was supported by grants from the Danish Cancer Society (Grant OKV 08007). Data has not previously been published.

\section{Author details}

${ }^{1}$ The Research Unit, Department of Palliative Medicine, Bispebjerg and Frederiksberg Hospitals and University of Copenhagen, Bispebjerg Bakke 23, DK-2400 Copenhagen, NV, Denmark. ${ }^{2}$ The Department of Health Services Research, Institute of Public Health, University of Copenhagen, Oster Farimagsgade 5, DK-1014 Copenhagen K, Denmark.

Received: 7 April 2014 Accepted: 22 July 2014

Published: 28 July 2014

\section{References}

1. Given BA, Given CW, Kozachik S: Family support in advanced cancer. CA Cancer J Clin 2001, 51:213-231.

2. Molassiotis A, Wilson B, Blair S, Howe T, Cavet J: Living with multiple myeloma: experiences of patients and their informal caregivers. Support Care Cancer 2011, 19:101-111.

3. Ellis J: The impact of lung cancer on patients and carers. Chronic Respir Dis 2012, 9:39-47.

4. Le T, Leis A, Pahwa P, Wright K, Ali K, Reeder B: Quality-of-life issues in patients with ovarian cancer and their caregivers: a review. Obstet Gynecol Surv 2003, 58:749-758.

5. Haley WE: Family caregivers of elderly patients with cancer: understanding and minimizing the burden of care. J Support Oncol 2003, 1:25-29.

6. Kotkamp-Mothes N, Slawinsky D, Hindermann S, Strauss B: Coping and psychological well being in families of elderly cancer patients. Crit Rev Oncol Hematol 2005, 55:213-229.

7. Resendes LA, McCorkle R: Spousal responses to prostate cancer: an integrative review. Cancer Invest 2006, 24:192-198.

8. Van Ryn M, Sanders S, Kahn K, Van Houtven C, Griffin JM, Martin M, Atienza AA, Phelan S, Finstad D, Rowland J: Objective burden, resources, and other stressors among informal cancer caregivers: a hidden quality issue? Psycho-Oncology 2011, 20:44-52.

9. Laizner AM, Yost LM, Barg FK, McCorkle R: Needs of family caregivers of persons with cancer: a review. Semin Oncol Nurs 1993, 9:114-120.

10. Blum K, Sherman DW: Understanding the Experience of Caregivers: A Focus on Transitions. Semin Oncol Nurs 2010, 26:243-258.

11. Blanchard CG, Albrecht TL, Ruckdeschel JC: The crisis of cancer: psychological impact on family caregivers. Oncology (Williston Park) 1997, 11:189-194.

12. Hagedoorn M, Buunk BP, Kuijer RG, Wobbes T, Sanderman R: Couples dealing with cancer: role and gender differences regarding psychological distress and quality of life. Psychooncology 2000, 9:232-242. 
13. Nijboer C, Tempelaar R, Sanderman R, Triemstra M, Spruijt RJ, van den Bos GA: Cancer and caregiving: the impact on the caregiver's health. Psychooncology 1998, 7:3-13.

14. Pitceathly C, Maguire P: The psychological impact of cancer on patients' partners and other key relatives: a review. Eur J Cancer 2003, 39:1517-1524.

15. Glajchen $\mathrm{M}$ : The emerging role and needs of family caregivers in cancer care. J Support Oncol 2004, 2:145-155.

16. Given B, Sherwood PR: Family care for the older person with cancer. Semin Oncol Nurs 2006, 22:43-50.

17. Kim Y, Given BA: Quality of life of family caregivers of cancer survivors: across the trajectory of the illness. Cancer 2008, 112:2556-2568.

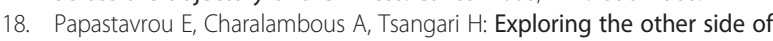
cancer care: the informal caregiver. Eur J Oncol Nurs 2009, 13:128-136.

19. Ko CM, Malcarne VL, Varni JW, Roesch SC, Banthia R, Greenbergs HL, Sadler GR: Problem-solving and distress in prostate cancer patients and their spousal caregivers. Support Care Cancer 2005, 13:367-374.

20. Tim Wong WK, Ussher J, Perz J: Strength through adversity: bereaved cancer carers' accounts of rewards and personal growth from caring. Palliative Supportive Care 2009, 7:187-196.

21. Ussher JM, Tim Wong WK, Perz J: A qualitative analysis of changes in relationship dynamics and roles between people with cancer and their primary informal carer. Health 2010, 15:650-667.

22. Lund L, Ross $L$, Groenvold M: The initial development of the 'cancer caregivng tasks, consequences and needs questionnaire' (CaTCoN). Acta Oncol 2012, 51:1009-1019

23. Kristjanson LJ: Validity and reliability testing of the FAMCARE Scale: measuring family satisfaction with advanced cancer care. Soc Sci Med 1993, 36:693-701.

24. Kristjanson $\sqcup$, Atwood J, Degner LF: Validity and reliability of the family inventory of needs (FIN): measuring the care needs of families of advanced cancer patients. J Nurs Meas 1995, 3:109-126.

25. Lund L, Ross L, Petersen MA, Groenvold M: The validity and reliability of the 'cancer caregiving tasks, consequences and needs questionnaire' (CaTCoN). Acta Oncol 2014, 53:966-974.

26. SAS Institute Inc: SAS/STAT 9.3 User's Guide. Cary, NC: SAS Institute Inc; 2011.

27. Payne $S, S$ mith $P$, Dean $S$ : Identifying the concerns of informal carers in palliative care. Palliat Med 1999, 13:37-44.

28. Vanderwerker LC, Laff RE, Kadan-Lottick NS, McColl S, Prigerson HG: Psychiatric disorders and mental health service use among caregivers of advanced cancer patients. J Clin Oncol 2005, 23:6899-6907.

29. O'Hara RE, Hull JG, Lyons KD, Bakitas M, Hegel MT, Li Z, Ahles TA: Impact on caregiver burden of a patient-focused palliative care intervention for patients with advanced cancer. Palliat Support Care 2010, 8:395-404.

30. Yabroff KR, Kim Y: Time costs associated with informal caregiving for cancer survivors. Cancer 2009, 115:4362-4373.

31. Van Houtven CH, Ramsey SD, Hornbrook MC, Atienza AA, Van Ryn M: Economic burden for informal caregivers of lung and colorectal cancer patients. Oncologist 2010, 15:883-893.

32. Girgis A, Lambert S, McElduff P, Bonevski B, Lecathelinais C, Boyes A, Stacey F: Some things change, some things stay the same: a longitudinal analysis of cancer caregivers' unmet supportive care needs. Psycho-Oncology 2013, 22:1557-1564

doi:10.1186/1471-2407-14-541

Cite this article as: Lund et al:: Cancer caregiving tasks and

consequences and their associations with caregiver status and the caregiver's relationship to the patient: a survey. BMC Cancer 2014 14:541.

\section{Submit your next manuscript to BioMed Central and take full advantage of:}

- Convenient online submission

- Thorough peer review

- No space constraints or color figure charges

- Immediate publication on acceptance

- Inclusion in PubMed, CAS, Scopus and Google Scholar

- Research which is freely available for redistribution 